\title{
Sustainable Leadership in Small Rural Schools: Selected Australian Vignettes
}

\begin{abstract}
According to Hargreaves and Fink (2003; 2006), sustainable leadership matters, spreads and lasts, and is fundamental to enduring and widespread school improvement. This observation is especially germane to the context of leading small primary schools in rural locations, where challenges encountered by principals in engaging with the complexities of continuous improvement are often accentuated. This article looks at the applicability of certain aspects of sustainable leadership to the circumstances surrounding small rural schools. First, reasons are given for devoting attention to the specific context of leadership in small rural primary schools, especially in Australia. The article then examines the distinctive challenges encountered by principals of small rural schools that appear to compound the difficulties of pursuing sustainable leadership. The next section draws from a Queensland study (Clarke \& Stevens, 2004) that has generated vignettes depicting the complexity of novice teaching principals' work in rural environments. Taking cognizance of Hargreaves and Fink's analysis of sustainable leadership, selections from these vignettes are used to sharpen understandings of ways in which sustainable leadership plays out in this context and the factors that either promote or impede its development.
\end{abstract}

Key Words: Context, Principal, Rural, School Improvement, Small Schools, Sustainable Leadership 


\section{Sustainable Leadership in Small Rural Schools: Selected Australian \\ Vignettes}

\section{Introduction}

As education reform continues apace in a range of international contexts, a good deal of interest in the concept of "sustainable leadership" has been generated (Fullan, 2005; Hargreaves \& Fink, 2003, 2006). According to Hargreaves and Fink, sustainable leadership matters, spreads and lasts, and is fundamental to enduring and widespread school improvement. Extrapolating from an understanding of sustainability in the environmental and corporate literature, these authors identified seven principles of sustainability in educational leadership (Hargreaves \& Fink, 2003) —which they have since expanded into a book, with some variations to the naming of the principles (Hargreaves \& Fink, 2006). In these publications they explain that leaders develop sustainability in many different ways, such as: by how they approach, commit to and protect deep learning in their schools; by how they sustain themselves and others around them to promote and support that learning; by how they are able and encouraged to sustain themselves in doing so, so that they can persist with their vision and avoid burning out; and by how they try to ensure the improvements they bring about last over time, especially after they have gone. 
Hargreaves and Fink's work (2003, 2006) draws heavily on a large-scale study of high schools in North America, against a background of demand for school improvement. We were interested in the relevance of their ideas in the particular context of leading small rural primary schools in Australia, where our previous work (Clarke \& Stevens, 2004; Clarke, Stevens, \& Wildy, 2006; Clarke \& Wildy, 2004) has indicated that the challenges encountered by these principals in engaging with the complexities of continuous improvement are often accentuated. This article looks more closely at the applicability of Hargreaves and Fink's three-dimensional concept of sustainable leadership-that it has depth, breadth, and length, or, that it matters, spreads, and lasts-to the circumstances surrounding small rural schools.

To begin, we outline some reasons why devoting attention to the specific context of leadership in small rural primary schools is warranted, especially in Australia. We then examine the particular challenges encountered by principals of small rural primary schools that appear to compound the difficulties of pursuing sustainable leadership. The next section of the article draws from a Queensland study (Clarke \& Stevens, 2004) that has generated vignettes depicting the complexity of novice teaching principals' work in rural environments. Taking cognizance of Hargreaves and Fink's (2003, 2006) analysis of sustainable leadership, we use selections from these vignettes to provide some glimpses of the ways in which sustainable leadership is played out in the challenging circumstances that are experienced by beginning principals in small rural primary schools. 


\section{Why focus on leadership of small rural schools?}

The reasons for our interest in leadership of small primary schools located in rural areas have been explained elsewhere (Clarke 2002; Clarke, Stevens, \& Wildy, 2006). It is helpful to reiterate these reasons briefly to provide some contextual background to the article. The first is their numerical significance: one quarter of all schools in the Queensland state education system are small, catering for fewer than 100 students, led by a principal who has a substantial teaching commitment (Lester, 2001). In Queensland the majority of these small schools are located in rural, remote and isolated environments, and a similar situation exists in South Australia (Barty, Thomson, Blackmore, \& Sachs, 2005) and Western Australia (Wildy \& Clarke, 2005). There are similar proportions of small schools in other Australian states (Murdoch \& Schiller, 2002), and although not always in remote areas, they are still small by necessity, not by choice.

Another more general reason for our interest in leadership of small rural primary schools is its potential impact in these situations. Mohr (2000) suggests in the US context that principals of small schools are much more immediately important to the day-to-day running of their organizations than their counterparts in larger schools because of the different ways in which small school communities relate to their leaders. Likewise, Weston (2000) and Southworth (2004) argue that the paramount influence of the principal in English small schools is underlined by Ofsted (Office of Standards in Education) inspection evidence. According to this 
evidence, principals of small primary schools tend to have more direct influence on the quality of teaching, providing them with powerful opportunities to bring about change and improvement. Furthermore, Southworth argues, principals of small schools have a significant mediated effect in addition to their direct effect: "they [know] that to change what [is] happening and to improve the schools they and other leaders [have] to influence indirectly and with determination, tenacity and a clarity of purpose" (p. 101).

Small schools, particularly when they are remote or isolated, can be vulnerable if their communities decline in employment opportunities and infrastructure (Pegg, 2007). In this connection, Barty et al. (2005) point to the unresolved equity issues arising from the difficulties in staffing remote schools, and The Bush Tracks Research Collective (2005) discusses the "very uneven" data on outcomes of schools in rural communities. Thus, from a social justice perspective it is vital that principals located in rural, remote and isolated environments are able to take advantage of powerful opportunities for change and improvement, because parents (and students) may have little option but to accept the educational provision on offer from the local school.

Considering the exigencies of recognizing, clarifying and valuing leadership of small rural schools, the dearth of research into leadership of these organizations (Southworth, 2004) is surprising, and provides another reason for our interest in investigating leadership in this specific context. 


\section{Challenges to developing sustainable leadership}

Opportunities for a principal to initiate, implement and sustain school improvement will be influenced strongly by the distinctive circumstances applying to the rural, remote or isolated small school. The trend from centralized education systems towards school-based management means that small schools are now subjected to heightened expectations as well as growing demands for accountability from parents, system administrators, and policy makers (Dunning, 1993; Hatton, 2001; Weston, 2000). The additional demands of administration imposed on principals who often spend substantial time in the classroom may be manifested in the so-called "double load", or the tension that arises between the professional concerns of teaching and the demands of management and leadership (Dunning, 1993; Hogden \& Wylie, 2005; Murdoch \& Schiller, 2002; Southworth, 2004; Wilson \&McPake, 2000).

The competing demands on teaching principals and the tensions they engender were evident in the findings of a survey investigating the work practices of 119 Queensland principals (Clarke, 2003). These teaching principals reported that the time they were spending on administration and management tasks had increased significantly in recent years. Many respondents also claimed they spent substantial time outside the normal school day on matters connected with curriculum, teaching and learning. Again, this is understandable, given that small schools have been required to cope with an enlarged curriculum and additional prescribed testing, within a demanding context of multi-age teaching and 
learning. The recent introduction of outcomes-based education has also necessitated teaching principals applying more sophisticated knowledge of curriculum planning and implementation than in the past.

The pressures stemming from the doubly loaded principal are accentuated by the isolation of small schools in rural/remote areas. There are limited opportunities for teaching principals located in such environments to exchange views and practice either within a school or beyond it. Fewer staff within the school obviously restricts collegial ways of operating and the tyrannies of time and distance deter teaching principals in remote areas from attending meetings and professional development events (Clarke, 2003; Hogden \&Wylie, 2005).

It has been suggested that "clustering" is important for facilitating the professional growth of teaching principals (Education Queensland, 2001). However, in spite of the demonstrable benefits of collaborative arrangements among small rural schools for enhancing teaching principals' efficacy, most respondents in the Queensland teaching principals' survey (Clarke, 2003) suggested that lack of time prevented them from developing and maintaining appropriate networks.

Isolation can also engender a milieu within a rural school's community that debilitates sustainable leadership. Given the extended and vital role that small schools perform in their community (Clarke, Stevens, \& Wildy, 2006; Nolan, 1998), the process of sustainable leadership is likely to be influenced by the ways 
in which the community is imbued with particular understandings of behavioral appropriateness and cultural expectations. For example, isolation can foster conservative attitudes in the community (Nolan, 1998), entailing a level of stability that is unconducive to sustainable reform. Stability influences the culture of the school because the staff in small rural schools is often drawn from the community itself and may also be long serving. Hence, newly appointed principals can encounter existing ways of doing things in the school shaped by tacit rules, expectations and activities which evolve into a culture of solidarity and comfortable co-existence (Clarke \& Stevens, 2006). The change process in these circumstances can be complex and slow. Also, teaching principals come and go, whereas the rest of the staff in a small rural school is usually more constant (Clarke \& Stevens, 2004). Opportunities are needed, therefore, for staff to build their professional capacity so that school improvement can be sustained regardless of the changeover of principals.

Conservatism can also engender a community culture that prescribes the behavior of residents and especially that of teaching principals (Yarrow, Herschell, \& Millwater, 1999). Principals who have difficulty in learning and displaying the types of behaviors expected of them in rural settings are at risk of "socio-cultural dislocation", thwarting their attempts to interact with the community (Lunn, 1997). Historically, engagement with the community has been more difficult for women principals because of a male-dominated ethos operating in these environments (Michael, 1996). From this perspective, parents and school community members have viewed the leadership role of the principal through the 
traditional stereotype of an authoritarian and preferably married man (D'Arcy, 1995; Dunshea, 1998).

The impact of the principals' involvement in community affairs for sustaining school change and improvement tends to be evolving in nature, and requires a long-term orientation. For many of these principals, however, their encounters with rural communities are "nasty, brutish and..short" and they do their time before returning to the city as quickly as possible (Ankrah-Dove, 1982, p. 11; Wallace \& Boylan, 2007). The rapid turnover of teaching principals in rural areas of Australia, therefore, is likely to undermine the degree of involvement necessary for sustaining school improvement initiatives (Wildy \& Clarke, 2005).

Lester (2001) has pointed out that $45 \%$ of teaching principalships changed hands over a 1-year period in a single region of Queensland. She suggests that this level of attrition is attributable to work overload and disillusionment amongst teaching principals, an interpretation that is borne out by the Queensland survey of teaching principals (Clarke, 2003). The survey indicated that the allencompassing nature of teaching principals' work has significant ramifications for their quality of life. Respondents' comments on this theme reflected a level of anxiety that detracts from job satisfaction. For example, reference was made to chronic fatigue and feelings of guilt when not attending to school matters. There were also concerns that performance of the role had to be compromised because of dealing with an unrealistically broad repertoire of professional responsibilities. Pressures of work and expectations were perceived to be so acute that they were a 
source of professional strain and personal dissatisfaction with professional self. Also evident in the survey was the detrimental impact of the teaching principal's onerous workload on family and personal life, emphasizing the difficulty of realizing a suitable work/life balance. Other large studies report similar ramifications of the overworked teaching principal (e.g., Hogden \& Wylie, 2005; Southworth, 2002).

High levels of attrition among teaching principals might also be attributable to a lack of preparation for the complexity of the role. The majority of respondents in the Queensland Teaching Principals Survey (Clarke, 2003) considered their most significant professional learning to have occurred on the job and by trial and error rather than through formal professional development activities. A minority of teaching principals located in isolated areas had participated in an induction process and many considered their induction to have been insufficient in preparing them for the role, a situation reported also by Murdoch and Schiller (2002). These deficiencies in preparation are perplexing given the inexperience of many teaching principals on their first appointment to small rural schools. The teaching principalship is often viewed as a stepping-stone for promotion, meaning that incumbents might well be dealing with whole school leadership for the first time.

The distinctive challenges for developing sustainable leadership in the context of small schools in rural/remote environments seem to represent what Fullan (2005, p. 53) describes as "adaptive problems". These are the kinds of problems 
for which we do not have the answers, which take time to deal with and, in Fullan's words, are "politically charged, as solutions are difficult to discern and learn and some disequilibrium on the way to addressing the problem is inevitable" (p. 54). With Fullan's observations in mind, we now draw on a Queensland study (Clarke \& Stevens, 2004) of the role of the teaching principal in small schools located in rural communities, to sharpen understandings of the ways in which sustainable leadership plays out in this context and, more particularly, the factors that either promote or impede its development.

\section{Methods}

To help understand how leaders of small schools in rural and remote locations deal with complexity in their work, four schools were selected for examination. The selection process involved a purposive sample of four teaching principals in their first year in the role, nominated by one district office. We focused on novice teaching principals because of our assumption that the challenges of the role were likely to be accentuated by inexperience. Indeed, we believe this is especially the case during the first few months of appointment. In Weindling's (1999) terms, this is the "entry and encounter" stage of the principalship when principals are developing a cognitive map of the complexities of the situation in which they find themselves, especially the people, the problems and issues, as well as the culture of the school and the community in which it is located. However, although the case studies focused on the novice leader, when a fourth novice principal was not 
available we included a slightly more experienced principal rather than limiting the sample to three, recognizing that data from this differing situation could offer other insights into small school leadership.

We conducted site visits to the four schools during the principals' first term of appointment. Two researchers spent one evening with the principal and two days in the school and community, so that greater contextual understanding of the environment in which these principals lived and taught could be gained. The site visits were followed by regular telephone and email interaction spread throughout a 2-month period to monitor the unfolding of particular tensions or dilemmas identified in the initial interviews. Principals were interviewed using semi-structured, in-depth interviews, which began by asking them to talk about their background and the circumstances of their appointment, and then encouraged them to identify and describe tensions and dilemmas encountered in the exercise of their roles. Discussions were also held with local stakeholders, such as community members, to provide information about the community context. These discussions concentrated on the expectations parents and community members hold of their principals and the issues they consider important in their local school.

Case accounts were then written for each site. This approach was chosen because we recognized that narrative or story is becoming an established way of revealing the human scale of teaching (Clandinin \& Connelly, 1991; Louden \& Wallace, 1996). We also saw the potential of the story as an effective means of depicting 
the complexity of teaching principals' work, characterized as it is by dealing with dilemmas, interacting with colleagues and the community, and coping with a broad range of professional responsibilities. More recently and in similar vein, Loder and Spillane (2006, p. 92) have advocated that in order to understand how the complexity of the principal's office is managed, there is a need "to pay attention to school leaders' personal and professional biographies as they interact with the particulars of the educational contexts in which they work". Presenting glimpses of these biographies in short vignettes, we felt, would allow readers to empathize with these teaching principals and gain insights into their circumstances-an approach, incidentally, which Hargreaves and Fink (2006) also employed, and for very similar reasons.

\section{The Participants}

Three of the four principals on whom the case studies were based were in their first year in the role; we have called them Chris, Greg and Kate. The fourth participant, whom we have called Phil, was in his third year as a permanent teaching principal (TP).

Chris, with 15 years teaching experience, had made a strategic career move to take up his TP position, relocating with his family from a contract appointment in far west Queensland to be closer to his extended family near the coast. Greg, who had a rapid rise to a teaching principalship in his fourth year of teaching, was in 
his first term as a TP. At the time of this study, his appointment was temporary, much to the dismay of the parent community, which had already witnessed a recent rapid turnover of acting principals. Although Greg had left a place he and his partner had liked and where they had a very strong friendship network, theylike Chris - had wanted to move closer to their respective families. Greg was keen to remain in his appointment and was proactive in learning every nook and cranny of the school's operations and in getting the school community onside by demonstrating his commitment in symbolic ways.

Kate, with seven years classroom experience behind her, was also on a temporary contract, and she found this restricting in a community of teachers and parents (a number of whom had also taught at the school) that was resistant to change. Furthermore, she was already a resident of the district when she took up the position, which facilitated her acceptance into the school community but also created some awkwardness. Her more intimate knowledge of the social dynamics of the community heightened her sensitivity to the implications of disturbing customary ways of doing things.

Phil had early ambitions of becoming a TP, and had been nurtured by a farsighted mentoring principal so that he was able to take on his first acting teaching principalship in only his fourth year of teaching. At the time of this study, he had completed a second challenging acting principalship and was in his third year as a permanent TP. As he explains it, he was able to make mistakes in those first two acting positions and then in his first permanent appointment got the chance to have 
a fresh start and knew what to avoid. As the examination of aspects of these teaching principals' vignettes will now illuminate, however, experience or lack of it is not the only factor that influences the development of sustainable leadership. In the next section we apply Hargreaves and Fink's $(2003,2006)$ three-dimensional concept of sustainable leadership-that it matters, spreads, and lasts-to the contextual circumstances in which principals of small rural schools do their work.

\section{Sustainable Leadership Matters}

According to Hargreaves and Fink (2003), leaders develop sustainability by how they approach, commit to and protect deep learning in their schools. These authors consider the first principle of sustainable leadership to be leadership for learning and leadership for caring for and among others (Hargreaves \& Fink, 2006, p. 18). From this perspective, it can be argued that the four leaders reported on here have a common commitment to deep learning, but their approaches vary.

Chris is cognizant of the fact that the community associated with a small, rural school can have very entrenched ways of operating, so he has embraced a "softly, softly" approach to leadership, and finds this works particularly well in the circumstances he has found himself. When I started at this school, I didn't want to change things too much. I thought it might get people off side if that happened. Also, I thought it might appear as some kind of judgment on how things were before ... generally in a small school you can make these changes and suggestions just by having a chat with 
people. Chris acknowledges that his commitment to improving the curriculum, in his own school and in the local cluster, means that he tends to put teaching and learning ahead of management and administration and he is gratified that the impact of this prioritization is becoming evident. Since I have been at the school I have been involved in activities to do with autism, reading programs, literacy, technology in the classroom, and more. The local cluster of six schools ... has provided me with professional support ... and we are doing curriculum planning together.

Greg felt that his main strength as a classroom teacher was bringing out the best in all of his students, and it had frustrated him to see that sometimes when students left his classroom they were not always motivated by other teachers. He was moved to apply for a TP position because he wanted to take more responsibility for the children and be able to make decisions that could make a difference. Greg's first appointment was to a school where there had been a high turnover of acting principals, so the parents wanted reassurance that he would be there for a whileyet he, also, was appointed as an acting principal. In an effort to give the impression of stability, which he realized was necessary to reassure parents and promote a constructive working partnership, he focused first on projects chosen for symbolic reasons that demonstrated his commitment to the school. For example, he improved the school's gardens and pledged to installing air conditioning to give the impression that he was going to be at the school for the long haul. As a result, he was soon accepted by the community and had the parents on side. Greg's commitment to improving deep learning in his school is achieved through motivating others: because I want to make the school better, so do 
they. He considers good communication-a skill he honed in various jobs before he became a teacher-essential, and believes he has helped to create at his school a productive culture based on mutual respect and trust. He has understood, therefore, the imperative of developing trusting relationships within and beyond the school for nurturing a learning-enriched environment.

In Kate's view, one of the attractions of the TP position was its capacity to give her more influence over whole-school matters: I'd be able to control where the school was going. If I wanted to meet student needs, I'd be able to do that more directly [than as a classroom teacher]. In order to deal with this expanded repertoire of professional responsibilities, her personal orientation to learning has had to change: she now sees herself very much as a learner. Whereas previously she was interested only in professional development opportunities for herself, her focus is now on those areas that will profit the school. In this regard, she is finding that talking with other principals, especially about the anecdotes from experienced principals at the small school cluster meetings, particularly helpful. She is also keen to keep those she refers to as the well educated people in this community ... [who] are genuinely interested in achieving best learning outcomes for the kids well informed about what is going on at the school, so that they continue to share her commitment.

Phil, like Chris, sees the classroom as his priority, although he admits that the double load of teaching and administration sometimes hampers his efforts. As a TP I am accountable for the learning of every single child here and I need a good 
working knowledge of how they learn and where they are.... Some days I see myself more as a principal, and other days more as a teacher. My view is that at the moment I need to maintain a focus on the classroom. Reflecting on his role, Phil affirms his belief that a TP in a small school is in a strong position to influence directly the quality of teaching and standards achieved. He is delighted that results of recent literacy and numeracy tests revealed that the trend was definitely upwards in terms of the students' learning, and he is also pleased with his approach to supporting that learning by supporting his teachers. One teacher who had been struggling with a new year level when I arrived had become a competent classroom practitioner by the end of the year.... [I realized] that not only had I spent the year trying to get on top of my game as a small school principal, but also that I had her knowing what to do.

\section{Sustainable Leadership Spreads}

According to Hargreaves and Fink (2003), leaders develop sustainability by how they sustain themselves and others around them to promote and support deep learning. For the leaders in this study, a common awareness is demonstrated in their stories of the need for and benefits of a professional support network in embedding sustainable leadership in their communities. This awareness is sharpened because of the isolation of many small schools in rural environments. These teaching principals' vignettes also demonstrate ways in which they sustain their teachers and the parent community to promote and support deep learning. 
Phil explains how he made it a priority to develop professional connections as soon as he took up his appointment. I made sure that I was proactive in developing a support network as quickly as possible. In the first instance I phoned up old colleagues for advice and then I started to work my way into the local network... There is a cluster of small schools which has been a fantastic source of professional support. I have also found that older principals in the area started to contact me and offer professional advice.... There is always the potential to experience professional isolation in a rural small school environment but I think it's easily overcome. It is vital that you make the effort to forge professional connections as quickly as possible.

One way in which Greg forged professional connections was by initiating a collaborative arrangement with the nearest school that enabled teachers to experience different roles and contexts for enhancing professional learning opportunities. Kate, though, ever mindful that hers was a temporary appointment, was more tentative than the other TPs in assuming her role. Initially, this tentativeness, coupled with her lack of previous leadership experience, detracted from her ability to lead and sustain change in her school. Nevertheless, once she realized how much her repertoire of professional responsibilities had extended as a TP from being a classroom teacher, Kate began to recognize the importance of building and maintaining a network for her professional sustenance. I'm finding the majority of my professional development at the moment is coming from talking to other principals... at the small school cluster meetings. This professional contact is then maintained via email. 
The influence of isolation on the distribution of sustainable leadership was also evident in the distance of rural schools from the Education Department's administrative offices because it had ramifications for the TP's ability to maximize the potential of their staff. While all found their District Office supportive, this was not always the case with the central human resources unit, which often appeared considerably removed from the vicissitudes of staffing realities in schools. In Greg's case, when I first contacted them they said, "Who are you?" They didn't even know where the school was.... I'm worried about the difficulties of communication with this office because staffing matters could be overlooked, which can have serious implications for the school. For example, we have a little girl with special needs who, although she was assessed four years ago, has not been getting the [support] that she was entitled to. In one of Chris's accounts, he tells how a lack of awareness from the human resources unit, again exacerbated by remoteness, was going to threaten the fragile stability he had nurtured in his school. I don't like Staffing; they tend to mess you around. They should be there to support you.

Chris's savvy in dealing with the vagaries of bureaucracy and acting diplomatically was highlighted as he sustained two teachers through a stressful staffing mishap while shielding the parent community from it. A teacher had been appointed to the school on a contract, and then without notice another (permanent) teacher was appointed, causing disruption for the former teacher, awkwardness for the TP, and annoyance for the parents. I just gave them the official Department line, as I was required to do. We put a positive slant on it... It was quite stressful for both teachers involved, and for me as manager of it. 
Sustaining those around them to promote and support deep learning is a recurring motif in the stories of these TPs. Phil does this by sharing authority and by ensuring open lines of communication, with both teachers and parents. It is essential for me to inform the parents about new practices ... to educate the parents so that they can make sense of what is happening ... keeping them informed keeps them onside. Chris supports his teachers by providing learning opportunities for them and by getting the sometimes sceptical parents to see what the teachers are achieving: What that teacher was achieving was amazing [but] they [the parents] had to see it for themselves. Greg imparts his motivation to his teachers-and to parentswho are then sustained by taking ownership of initiatives. One of my staff has just cancelled long service leave because it would interrupt an IEP [Individual Educational Program] that has just begun. She wants to do the best job she can.... One of the parents who knows the school is doing everything we possibly can for her daughter is going to repaint the tuckshop... and her husband [is helping] ... they are also motivated to help. I can count on their support because that is the environment I've helped to create-we support each other. Kate's parent community is very supportive if it improves the learning environment for their children ... they are into giving the kids experiences, so Kate finds she can tap into their resourcefulness.

Greg frequently reiterates that he gained his leadership position because he was actively mentored by a former principal. He now realizes that he can also nurture others who have the characteristics he admires, and in doing so can build effective partnerships for learning. Recently a partnership has developed with a local school which is going to allow me to do that. I visited an interesting program at that 
school and developed an immediate rapport with the principal there. She is very charismatic and it will be easy to work with her towards a Partners for Success initiative. There is a young teacher at that school who has leadership aspirations. I realized that I could offer her opportunities in my school.... I can see the partnership with this school having other advantages as well. They have a special teaching program going on there... we can benefit from their different outlook.

\section{Sustainable Leadership Lasts (Endurance)}

Endurance and succession are the two facets of Hargreaves and Fink's key principle of sustainable leadership-length. According to Hargreaves and Fink (2003), leaders develop sustainability firstly by how they are able to endure: to persist with their vision and avoid burning out.

There are a lot of demands on the teaching principal in a small community, and I knew I had to strike a balance. So Chris explained, before elaborating on some of those multiple demands and how he was managing them. Accessibility can be a doubleedged sword for the TP in any small school, but particularly in a rural or remote community of which the school is an integral part. A longstanding member of one of these school communities explained it thus: People use the principal as a father confessor. I don't know why that is, but it might be because there's no one else to look up to in that way. As Chris found, sometimes you have to do social work, which didn't 
happen as a classroom teacher.

"Striking a balance" was essential for Chris if he was to persist with his vision and avoid burning out, but as he acknowledges, his maturity and previous experience assisted him in developing this sustainability. Chris recognizes that he can be effective as a TP only if he maintains perspective, and that sometimes he will need to escape from the pressures of his role.

Phil's vignettes also underscore the tensions involved in balancing engagement in the community with his private life. On the one hand, you're not just here to be the principal of the school-you're here to be one of them, and to this end Phil made the effort to get out and work alongside them in their projects. He was cognizant of the fact that he needed to be accepted by the community if they were going to be supportive of his vision for the school, but that this acceptance would take time. People in a small community tend to be a little more conservative.... It takes time for people to work out who you are and what you stand for and to decide whether or not they can trust you. Phil was as proactive socially as he was professionally, but his expanded social engagement then required boundaries if it was not to wear him out. At times it did get tough, and it probably had a lot to do with the high workload.... I sometimes yearned to talk to people who were outside of the school situation. If I really wanted to get away and be by myself, I would go off fishing.

Maturity and previous experience assisted Greg, like Chris, in keeping a sense of perspective. He was confident in assuming the TP position, but realized that his 
commitment to the role would need to be supported by efficiency in time management. Beyond that, Greg highlights the critical importance of a supportive partner. I put in $110 \%$, but I couldn't do it if my personal life wasn't spot on, and I'd hate to take on a job like this on my own.

\section{Sustainable Leadership Lasts (Succession)}

According to Hargreaves and Fink (2003), leaders develop sustainability secondly by how they try to ensure the improvements they bring about last over time, especially after they have gone. Given the vagaries of staffing within education departments, as well as the dynamics of the teaching team they might be leaving behind, this can be particularly challenging for TPs of small rural schools. Phil's and Kate's stories both highlighted the resistance to change they encountered. Kate felt so hampered by it that she was reluctant to suggest improvements, whereas Phil realized that he would have to canvas his plans widely if he were to have any chance of having them accepted. In Greg's case, once he had done the "spadework" to get his community onside, he found it easier to implement improvements, whereas Chris's task was not as easy because he was following a good principal.

Chris tells this story. Before I arrived, there had been a succession of acting principals and people were pretty sick of it. My predecessor had done a lot of good work in the 
community, but was unable to keep the position. During the pupil free day before I started teaching here, a parent approached me and bluntly said, "We don't want you; we like the other bloke and tried very hard to keep him here." I talked with him and emphasized the kids; he was worried about them and I would have been too, given the high turnover of acting principals. If I'd been a younger principal I don't know how I would have handled it. It takes time to build trust. I've noticed that other parents now take the initiative to approach me.

Chris realizes that he has a responsibility to build the capacity of the staff in order to ensure that the momentum of school improvement is maintained after he has gone. I think it's my responsibility to provide learning opportunities for my staff.... In a small school, there's no point in the principal learning new skills and then moving on, taking those skills with them.... The continuity of professional learning needs to be there for the people who are going to be in the school after you've left, and that includes staff and students.

\section{Discussion}

Bajunid (2006) has pointed out that the principles of sustainable leadership identified and explained by Hargreaves and Fink (2006) are powerful, relevant and useful tools and that as such, they can be enriched as they are applied to individuals' own experiences. Accordingly, this article has concurred with the 
main tenets of sustainable leadership espoused by Hargreaves and Fink (2003, 2006), but in presenting some particularities to illustrate their generalities, it has also demonstrated some of the challenges to developing sustainable leadership, and how these challenges can be accentuated by the complexities inherent in the context of small rural schools. The teaching principals featured in the study from which this article has drawn exhibited aspects of sustainable leadership in individual ways, but they did so in response to individual circumstances, and faced with challenges, the commonalities of which are discussed below.

\section{$\underline{\text { Sustainable Leadership Matters }}$}

Our vignettes have suggested that for the TPs involved in the study, sustainable leadership is extremely important to the way they do their work. Their approaches vary, but in all cases it is fair to say that sustainable leadership is especially difficult to achieve in the small rural school context. In particular, the fidelity of sustainable leadership was occasionally compromised because the principals had been appointed on short-term contracts and this arrangement undermined the prospects of enduring and widespread school improvement. Short-term contracts dissuade principals from investing in their schools and communities and tend to make them tentative in their approach to bringing about change and improvement. Even more deleterious to the prospects of sustainable leadership is the connection between short-term contracts and rapid turnover of TPs. Involvement of the principal in community affairs tends to be 
enhanced with the adoption of a long-term orientation because it takes time for trusting relationships between principal and broader community to evolve. The transience that is integral to the "revolving door" principalship, which is a common feature of small rural schools, weakens capacity to develop productive partnerships with the community and is damaging to enduring school improvement.

Hargreaves and Fink (2006, pp. 272-273) urge that for this reason, sustainable leadership must be the responsibility of national, state and provincial spheres:

If change is to matter, spread, and last, sustainable leadership that stretches across many leaders must now also be a fundamental priority of the systems in which leaders do their work. Sustainability is the first and final challenge of leadership. And it is the biggest challenge to the highestlevel leaders of all-those in our national and state governments.

\section{Sustainable Leadership Spreads}

Our vignettes also highlight that the difficulties entailed in the distribution of leadership are compounded by isolation. Professional isolation determines that there is an imperative for TPs to develop networks for their professional sustenance and to share resources for mutual benefit. Also, there is evidence in these vignettes of TPs having to contend with "bureaucratic isolation", a kind of system anonymity, which can occur elsewhere but is accentuated in rural and 
remote school contexts. In these contexts the impact of proximity is especially pronounced with district offices and, to an even greater extent, central office, being geographically and psychologically far removed from the real world of the TP in a small rural school.

It seems that policy makers and system administrators do not always consider small schools to be discrete elements within a diverse educational system. This oversight may lead to system administrators overestimating the capacity of individual principals to implement externally mandated changes as well as underestimating a school's specific priorities for improvement. Perhaps this affirms a common community perception that policy makers have a preoccupation with issues and challenges associated with urban schooling (Dunning, 1993). From this perspective, small rural schools are deemed to be relatively low status institutions because in education systems it is size that matters and bigger schools are usually regarded as more important than small ones (Murdoch \& Schiller, 2002; Southworth, 1999, 2004). It also suggests that policy makers need to re-examine their thinking through the application of a "rural lens" rather than according to an urban and bureaucratic purview (Wallace \& Boylan, 2007). A rural lens requires a nuanced understanding of rural places engendering an acknowledgement of the distinctiveness of the rural environment at the macro level as well as recognition of the differences between rural schools at a micro level. 
The notion of the rural lens has been influenced by Ankrah-Dove's useful articulation (1982) of two competing sets of assumptions about the quality of life in rural and remote areas, which engender very different policy implications for attracting and retaining teachers. Firstly, Ankrah-Dove identifies the "rural deficit" model, which we would suggest has traditionally informed policy makers and system administrators in their understanding of rural education and their decision making.

As the term would indicate, the rural deficit model highlights the deficiencies of living and working in rural environments, a corollary of which is the assumption that service in rural areas needs to be enforced. Hence, according to Ankrah-Dove (1982), there tends to be a reliance on strategies such as compulsion and incentives in order to staff rural schools. Although these strategies might be expedient in the short term, they are unlikely to promote the level of commitment and stability among appointed staff over the longer term.

As an alternative approach, Ankrah-Dove (1982) advocates the "rural challenge" model, which is predicated on the belief that working in rural schools, for those who are able to cope, provides them with distinctive professional challenges and interests. From this perspective, the focus is on encouraging teachers to envisage their time in rural postings as a career-long prospect. Therefore, rather than relying on strategies such as compulsion and incentives to induce teachers to fill vacancies in rural schools, the emphasis in the rural challenge model is placed on professional learning and development that empowers teachers to develop the 
self reliance necessary to meet the challenges of living and working in rural and remote areas.

Notwithstanding Ankrah-Dove's more specific concern (1982) with enhancing the quality of teachers in rural and remote locations, we would argue that the rural challenge model she articulated over 25 years ago can provide a powerful mental model for facilitating sustainable leadership in rural/remote contexts.

\section{Sustainable Leadership Lasts}

Hargreaves and Fink (2003) refer to leaders being "able and encouraged" to sustain leadership. Clearly the professional responsibilities required of TPs in small rural schools are wide ranging. One of the main challenges, however, for the TPs whose vignettes have been examined in this article was the visibility engendered by principals living and working in small, tightly-knit rural communities and their need to strike a balance between engaging with the community and at the same time maintaining professional distance. This distinctive characteristic of a TP's day-to-day work in the context of a rural community is always demanding, occasionally debilitating, and requires the principal to devise strategies for dealing with increased stress. An ability to keep a sense of perspective in dealing with tensions between professional and private spheres of life appears to be a particularly significant influence on these principals' capacity to develop resilience. It is also clear that partners and families 
provide much needed sustenance, especially for those TPs grappling with the complexities of the task for the first time. Similarly, Loder and Spillane (2006) comment on the need for accommodating systems of family support to enable (women) principals to cope with their multiple and competing roles. There does seem, however, to be an onus on the TPs to take care of themselves and it should not be overlooked that the system itself also has a responsibility to contribute to their leaders' wellbeing in order to prevent them from burning out (Hargreaves \& Fink, 2003).

Furthermore, all the TPs in the study were aware of the need to ensure that their improvements would last over time, especially after they had gone. What their vignettes highlight are the challenges to this intention presented by the reality of small rural school contexts. Once again, these challenges include appointments being made on temporary contracts and the associated high turnover of principals that disrupts the continuity of school improvement. In rural communities where the school is likely to play a central role, a rapid succession of principals tends to be resented by local residents and prevents incumbents from building and sustaining robust school-community partnerships that are fundamental to ongoing improvement.

Another distinctive challenge to bringing about improvements that last, especially after the principal has gone, is presented by the stability of a school's existing ways of operating, resulting in the change process being complex and slow. Also, if TPs are likely to come and go while the rest of the staff remains 
constant, there is a heightened temptation for teachers to wait out their principals (Hargreaves \& Fink, 2003), with the danger that improvements end up being ephemeral and episodic.

\section{Final Comments}

In sum, this article has highlighted two key points pertinent to the "how" of sustainable leadership. First, the ways in which school leaders develop sustainable leadership are mediated by their contextual circumstances. Although the basic tenets of sustainable leadership seem to be inviolable, we would argue that the processes by which it is attained are necessarily flexible and will vary significantly according to the complexities of the situation in which school leaders find themselves, especially the people, the problems and issues, as well as the culture of the school and the community in which it is located.

From this perspective sustainable leadership is enhanced considerably by school leaders, and especially principals, being "contextually literate" (National College for School Leadership, 2007). This need for school leaders to be able to read the complexities of their contexts is not confined to those working in small rural communities; nevertheless, we have demonstrated that sensitivity to context is exceptionally important for leaders located in these kinds of settings. Rural communities tend to be distinguished by a profound sense of place because they are imbued with particular societal and cultural values, some of which may 
appear unusual from the urban perspective that many principals will have acquired before appointment. This observation reiterates the value of adopting a rural lens (Wallace \& Boylan, 2007) to which we have referred earlier in the article.

At an individual level a rural lens helps principals become appropriately attuned to the sense of place. It is informed by a viewpoint that stresses the challenges of the environment rather than its deficits and values longer-term purposes to bring about educational improvement rather than short-term expediency (AnkrahDove, 1982; Wallace \& Boylan, 2007). The longer-term orientation is likely to facilitate the community's trust in the principal as well as enabling priorities to be determined for promoting school improvement that are needs based.

The desirability of principals acquiring a rural lens as a strategy for enhancing sustainable leadership has important implications for their initial preparation and also for their ongoing professional learning. In particular, it implies that leadership development programs would benefit from giving greater attention to enhancing knowledge of the school in a community, how communities work and how principals can interact effectively with community partners, as Ankrah-Dove exhorted in 1982 when she argued for school systems to adopt a rural challenge model of teacher preparation.

This consideration of the efficacy of leadership development processes for principals appointed to small, rural schools is pertinent to the second key point 
that has been highlighted in the article. At a purely pragmatic level, this article affirms the critical observation made by Hargreaves and Fink (2003, p. 10) that "sustainable leadership certainly needs to become a commitment of all school leaders, but if change is to matter, spread and last, sustainable leadership must also be a fundamental priority of the systems in which leaders do their work." One inescapable requirement of this priority is effective succession planning to ensure there are "flows of leadership across many years and numerous people" (Hargreaves \& Fink, 2006, p. 5). This, however, has been a perpetual challenge in rural and remote contexts and one that education systems have found difficult to resolve.

Once again, if education systems as a whole are to embrace a constructive approach to succession planning in rural and remote regions, it is helpful to refer to the notion of the rural lens. Policy makers and system administrators who examine the implications of succession planning through a rural lens will be more inclined to consider the distinctiveness of rural and remote communities in order to rethink ways in which appropriate educational leadership can be nurtured within these environments. At the very least, these strategies should include a reexamination of how principals are currently prepared, developed and supported to work in rural communities, so they are more likely to find such postings appealing and are better equipped to make a difference to the performance and vitality of the schools and communities they serve. 


\section{References}

Ankrah-Dove, L. (1982). The deployment and training of teachers for remote rural schools in less-developed countries. International Review of Education, 28(1), 3-27.

Bajunid, I. A. (2006). Andy Hargreaves and Dean Fink, Sustainable Leadership (Book Review). Journal of Educational Change, 7, 105-107.

Barty, K., Thomson, P., Blackmore, J ., \& Sachs, J . (2005). Unpacking the issues: Researching the shortage of school principals in two states of Australia. Australian Educational Researcher, 32(3), 1- 14.

Clandinin, D. J., \& Connelly, F. M. (1991). Narrative and story in practice and research. In D. Schon (Ed.), The reflective turn. Case studies in and on educational practice (pp. 258-281). NewYork: Teachers College Press.

Clarke, S. (2002). The teaching principal: From the shadowlands to a place in the sun. Queensland Journal of Educational Research, 18(1), 23-37.

Clarke, S. R. P. (2003). Mastering the art of extreme juggling: An examination of the contemporary role of the Queensland teaching principal. Unpublished report on the Queensland Association of State School Principals (QASSP) teaching principals' survey. 
Clarke, S., \& Stevens, E. (2004). Small schools leadership study. Leading and teaching in small schools: Confronting contextual complexity in work practices. Report prepared for Education Queensland.

Clarke, S., \& Stevens, E. (2006). Spatial engagement: The navigation of a novice teaching principal in a small rural community. Studies in Learning, Evaluation, Innovation and Development, 3(1), 12-26. Retrieved March 7, 2007, from http:// sleid.cqu.edu.au

Clarke, S., Stevens, E., \&Wildy, H. (2006). Rural rides in Queensland: Travels with novice teaching principals. The International Journal of Leadership in Education, 9(1), 75-88.

Clarke, S., \&Wildy, H. (2004). Context counts: Viewing small school leadership from the inside out. Journal of Educational Administration, 42(5), 555-572.

D’Arcy, J . (1995). Musings of a female principal. In B. Limerick \& B. Lingard (Eds.), Gender and changing educational management (pp. 209-211). Second Year Book of the Australian Council for Educational Administration. Rydalmere, N.S.W: Hodder Education.

Dunning, G. (1993). Managing the small primary school: The problem role of the teaching head. Educational Management and Administration, 21(2), 79-89. 
Dunshea, G. (1998). Beginning principals and the issue of gender in rural and regional areas. Asia-Pacific Journal of Teacher Education, 26(3), 203-215.

Education Queensland. (2001). Report of the Schools with Teaching Principals Project. Brisbane: Education Queensland.

Fullan M. (2005). Leadership \& sustainability: System thinkers in action. Thousand Oaks: Corwin Press.

Hatton. E. (2001). School development planning in a small primary school. Addressing the challenge in rural NSW. Journal of Educational Administration, 39(2), 118-133.

Hargreaves, A., \& Fink, D. (2003). The seven principles of sustainable leadership. Retrieved March 7, 2007, from ww2.bc.edu/ _hargrean/docs/seven_principles.pdf

Hargreaves, A., \& Fink, D. (2006). Sustainable leadership. San Francisco: J ossey Bass.

Hodgen, E., \&Wylie, C. (2005). Stress and wellbeing among New Zealand principals. Report to the New Zealand Principals' Federation. Wellington: New Zealand Council for Educational Research Te Rünanga O Aotearoa Mö Te Rangahau I T E Mätauranga. 
Lester, N. (2001). Teaching principals: Their background, experience and preparedness for the role. The Practising Administrator, 23(4), 17-21.

Loder, T. L., \& Spillane, J . L. (2006). Big change question: How do leaders' own lives and their educational contexts, influence their responses to the dilemmas and tensions they face in their daily work? Journal of Educational Change, 7, 91-92.

Louden, W., \&Wallace, J . (1996). Quality in the classroom: Learning about teaching in the classroom. Rydalmere, N.S.W: Hodder Education.

Lunn, S. (1997). Rural strategies project. Brisbane: Priority Country Area Program.

Michael, A. (1996). Issues facing women as principals in rural and remote areas. Report prepared for the Queensland Teachers Union.

Mohr, N. (2000). Small schools are not large schools. Potential pitfalls and implications for leadership. In W. Ayers, M. Klonsky, \& G. Lyon (Eds.), A simple justice: The challenge of small schools (pp. 139-158). New York: Teachers College Press.

Murdoch, D., \& Schiller, J . (2002, December). Teaching principals in smaller primary schools: Their issues, challenges and concerns. Paper presented at the AARE Conference, Brisbane. Retrieved March 7, 2007, from 
http:/ / www.aare.edu.au/ 02pap/ mur02145.htm

National College for School Leadership. (2007). What we know about school leadership. Retrieved J anuary 25, 2008, from http://www.ncsl.org.uk/ publications

Nolan, B. (1998). Implementing departmental policy changes in one-teacher schools. Journal of Educational Administration, 36(3-4), 262-285.

Pegg, J . (2007). Developing a national, holistic approach to addressing issues in rural and regional schools education. In N. Rees, D. Boyd, \&E. Terry (Eds.), 23 ${ }^{\text {rd }}$ National Rural Education Conference Proceedings. Collaboration for success in rural and remote education and training (pp. 2-14). Perth: SPERA.

Southworth, G. (1999). A teacher training agency report into successful heads of small primary schools. Reading: University of Reading School of Education.

Southworth, G. (2002). Lessons from successful leadership in small schools. In K. Leithwood, P. Hallinger, K. Seashore Louis, P. Gronn, G. Furman-Brown \& J . Macbeath (Eds.), Second international handbook of educational leadership and administration (pp. 451-458). Dordrecht: Kluwer Academic Publishing.

Southworth, G. (2004). Primary school leadership in context: Leading small, medium 
and large sized schools. London \& New York: RoutledgeFalmer.

The Bush Tracks Research Collective. (2005, November). Bush tracks: Exploring rural teaching transitions. Paper presented at the annual meeting of AARE, Parramatta, UWS. Retrieved March 7, 2007, from http:// www.aare.edu.au/ 05pap/ mcc05688.pdf

Wallace, A., \& Boylan, C. (2007). Reawakening education policy and practice in rural Australia. In N. Rees, D. Boyd, \&E. Terry (Eds.), 23rd National Rural Education Conference Proceedings. Collaboration for success in rural and remote education and training (pp. 15-29). Perth: SPERA.

Weston, P. (2000). Working together in partnership. Collaboration, confederation or federation: What's best for small primary schools in Leicestershire. Retrieved March 7, 2007, from http:// www.pqa.org.uk/small_schools.htm

Weindling, D. (1999). Stages of headship. In T. Bush, L. Bolam, R. Glatter, \&P. Ribbins (Eds.), Educational management: Redefining theory, policy and practice (pp. 90-101). London: Paul Chapman Publishing.

Wildy, H., \&Clarke, S. (2005). Leading the small rural school: The case of the novice principal. Leading \& Managing, 11(1), 43- 56.

Wilson, V., \&McPake, J . (2000). Managing change in small Scottish primary 
Schools: Is there a small school management style?. Educational

Management Administration \& Leadership, 28, 119-132.

Yarrow, A., Herschell, P., \& Millwater, S. (1999). Listening to country voices: Preparing, attracting and retaining teachers for rural and remote areas. Education in Rural Australia, 9(2), 1-12. 